\title{
MODELING OF HONEY HEATING IN RECRYSTALLIZER
}

\author{
Dmitry Ovsyannikov, Sergei Oskin, Artyom Lytnev, Dmitry Tsokur \\ Kuban State Agrarian University named after I.T. Trubilin, Russia \\ ovs@medovs.ru,kgauem@yandex.ru, artemlytnev@mail.ru,dmitry_tsokur@mail.ru
}

\begin{abstract}
Currently, retail chains have serious requirements for packaged honey. First of all, it is an attractive look for a buyer, which should not change over time. Despite the great effort required to obtain natural honey in an apiary, even more labor is demanded for its further processing in connection with the production requirements. In this situation, trying to invest in the cost of packing honey and please customers, manufacturers subject honey to serious heating. Overheating of honey sharply reduces its quality, it loses antimicrobial properties, diastase activity decreases, vitamins are destroyed, sugars are decomposed, resulting in accumulation of oxymethylfurfural, coloration increases and flavor worsens. But today, heating is an integral part of the production process of competitive honey, its filtration and packaging. Due to the current situation on the market, it is impossible to exclude heating of honey from the production process, since it is impossible to get honey that meets the requirements of retail chains and ordinary customers without it. The article shows that it is possible to increase the competitiveness of natural honey without losing its quality by justifying the parameters and modes of the technological process of heating honey in a recrystallizer. A mathematical model of this process was obtained and its mathematical processing was performed using the Comsol Multiphysics 5.4 program. The article describes in detail all stages of creating a model in this program. The resulting mathematical model takes into account the thermophysical parameters of honey, the geometric dimensions of the recrystallizer and allows to implement various options for regulating the temperature of honey, as well as to justify the effective location of the temperature sensor to prevent overheating of honey.
\end{abstract}

Keywords: honey, recrystallizer, thermal model, temperature sensor, Comsol Multiphysics.

\section{Introduction}

In the current conditions of globalization and market economy in Russia, retail chains are becoming increasingly attractive for customers. As a result of the outflow of buyers to supermarkets, natural honey in the markets and fairs to sell is becoming less profitable, as labor costs for its implementation is not comparable to the income from its sale. The reason for this is the changed preferences of buyers, as well as serious demands for honey from retail chains, which do not correspond to honey sold in the markets. All this will soon lead to the fact that honey in Russia will disappear from the markets and will only be sold on the shelves. But there is a big difference between honey at the market and at the supermarket. Retail chains have serious demands on packaged honey. First of all, it is an attractive look for the customer, which should not change for a long time [1;2].

Despite the great effort required to produce natural honey at the apiary, even greater labor costs require its further processing in connection with the requirements of retailers. In this situation, trying to invest in the cost of packaging honey and to please customers, manufacturers add various additives and, most importantly, subject honey to rough heating! According to Russian and foreign researchers overheating of honey in the recrystallizer sharply reduces its quality, antimicrobial properties disappear, diastase activity decreases, vitamins are destroyed, sugars decompose, as a result oximethylfurfural accumulates, chromaticity increases, aroma worsens (Fig 1) [3-8].

As a result of unscrupulous processing, honey loses its naturalness and becomes completely useless. But today, heating is an integral part of the technological process of producing, filtering and packaging competitive honey.

For honey heating special equipment - recrystallizers are used. Now there are two known manufacturers of recrystallizers: in Russia firm "BiProm", in Poland firm "Lyson" [9]. Heating in such installations can be regulated in wide enough limits from 20 to $90^{\circ} \mathrm{C}$. But in spite of available inventory, there are still no parameters and modes of operation, at which natural properties of honey would be kept. In our opinion, to increase competitiveness of natural honey without loss of quality of production is possible by substantiation of parametres and modes of the electrotechnological process of heating honey in the recrystallizer.

For this purpose it is necessary, first of all, to create a model of honey heating in the recrystallizer, which will speed up the process of finding the parameters and heating modes, as well as determine the best design parameters of the installation, such as the optimal location of the temperature sensor. The 
main purpose of modeling is to determine the parameters and modes of operation of the plant without loss of honey quality.
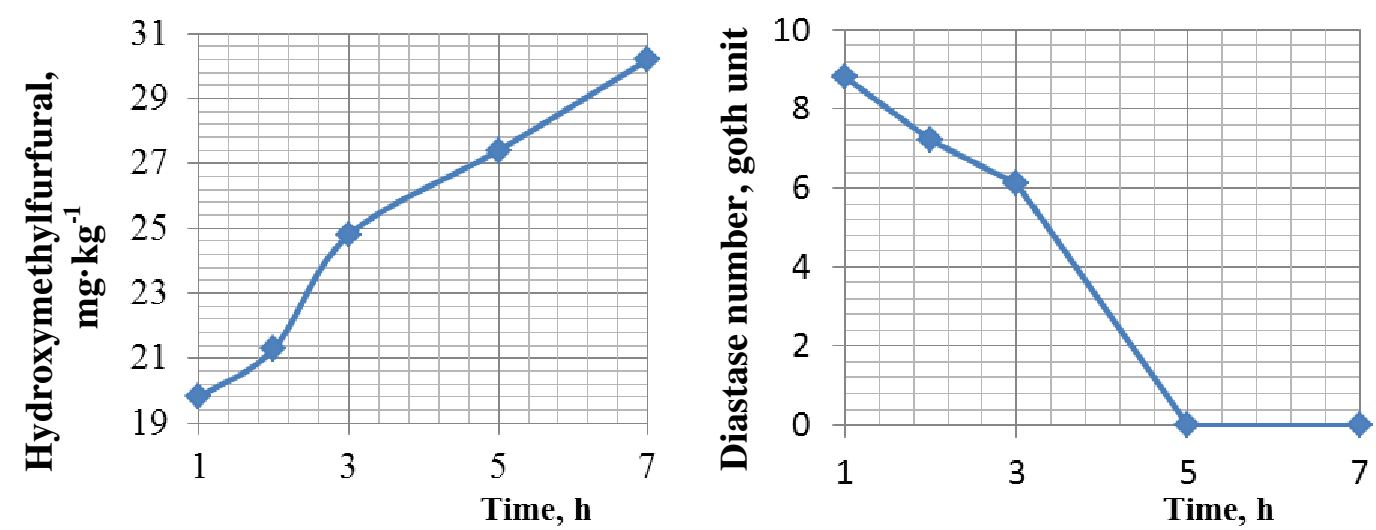

Fig. 1. Increasing oxymethylfurfurol, when honey is heated to $70{ }^{\circ} \mathrm{C}$ for 7 hours (left), decreasing diastatic number, when honey is heated to $70^{\circ} \mathrm{C}$ for 7 hours (right)

\section{Materials and methods}

The recrystallizer model was developed on the basis of a design by the Russian company "BiProm". Recrystallizer is a cylindrical container, in the walls and at the bottom of which there are film heaters. The unit also has a stirrer for short-term mixing of honey in order to equalize its temperature. From above, the recrystallizer is closed with a lid made of plexiglass. There is an air gap between the lid and the honey filled into the unit. The following assumptions have been made.

1. In the air gap free convection was taken into account, which can be described on the basis of Navier-Stokes equations [10]:

$$
\left\{\begin{array}{l}
\frac{\partial \rho}{\partial t}+\nabla \cdot(\rho u)=0 \\
\rho \frac{\partial u}{\partial t}+\rho u \cdot \nabla u=-\nabla p+\nabla \cdot\left(\mu\left(\nabla u+(\nabla u)^{T}-\frac{2}{3} \mu(\nabla \cdot u) I\right)\right)+F+\rho g
\end{array}\right.
$$

where $\rho$-air density, $\mathrm{kg} \cdot \mathrm{m}^{-3}$;

$u$ - air velocity, $\mathrm{m} \cdot \mathrm{s}^{-1}$

$p$ - pressure, $\mathrm{Pa}$;

$\mu$ - dynamic air viscosity index, $\mathrm{Pa} \cdot \mathrm{s}$;

$I$ - identity matrix;

$F$ - volume force vector, $\mathrm{N} \cdot \mathrm{m}^{-3}$;

$\rho g$ - force of gravity, $\mathrm{N}$.

2. Free convection in honey is not considered due to its high viscosity. Honey is only heated by its thermal conductivity:

$$
\rho C_{p} \frac{\partial T}{\partial t}+\rho C_{p} u \cdot \nabla T+\nabla \cdot q=Q
$$

where $C_{p}$ - honey heat capacity, $\mathrm{J} \cdot(\mathrm{kg} \cdot \mathrm{K})^{-1}$;

$Q$ - heat source capacity, $\mathrm{W} \cdot \mathrm{m}^{-3}$;

$q$ - heat flux density, $q=-k \nabla T, \mathrm{~W} \cdot \mathrm{m}^{-2}$;

$k$ - thermal conductivity of honey, $\mathrm{W} \cdot(\mathrm{m} \cdot \mathrm{K})^{-1}$;

$T$ - temperature, $\mathrm{K}$.

3. Heat transfer of the recrystallizer with the environment is carried out through free convection. For the vertical wall of the recrystallizer casing, the heat transfer coefficient is determined by the following formula [11]: 


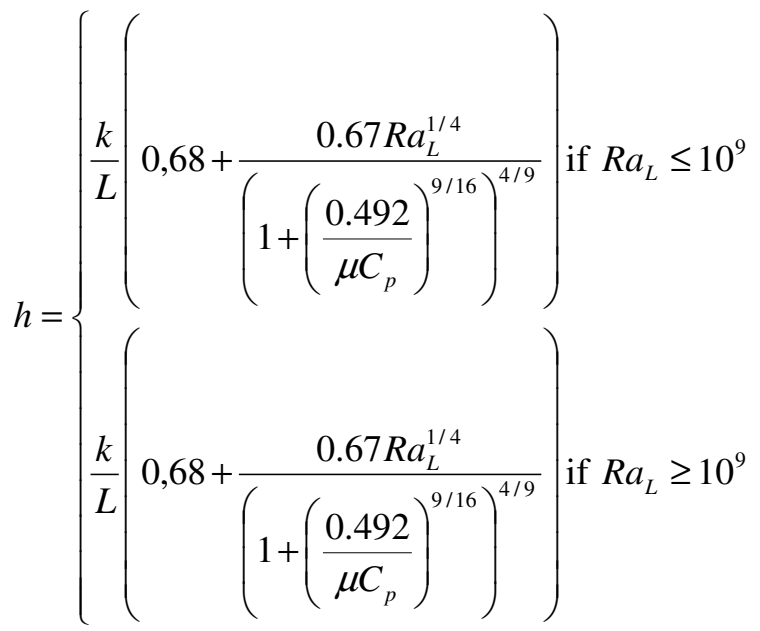

where $h$ - heat transfer coefficient, $\mathrm{W} \cdot\left(\mathrm{m}^{2} \cdot \mathrm{K}\right)^{-1}$

$L$ - wall height, m;

$R a_{L}-$ Rayleigh number.

$$
R a_{L}=\frac{g \alpha_{p} \rho^{2} C_{p}\left|T-T_{e x t}\right| L^{3}}{k \mu}
$$

where $g$-acceleration of gravity, $\mathrm{m} \cdot \mathrm{s}^{-2}$;

$\alpha_{P}-$ coefficient of thermal expansion in a fluid, $\mathrm{K}^{-1}$;

$T_{e x t}-$ external temperature, $\mathrm{K}$.

Then, the heat flow $q_{0}$ through the wall of the recrystallizer casing $\mathrm{W} \cdot \mathrm{m}^{-2}$ :

$$
q_{0}=h\left(T_{\text {ext }}-T\right)
$$

Modeling was performed in Comsol Multiphysics 5.4. In this program a geometrical model of the honey recrystallizer was created. For this purpose the ossimmetric model was chosen to simplify the calculation (Fig. 2).

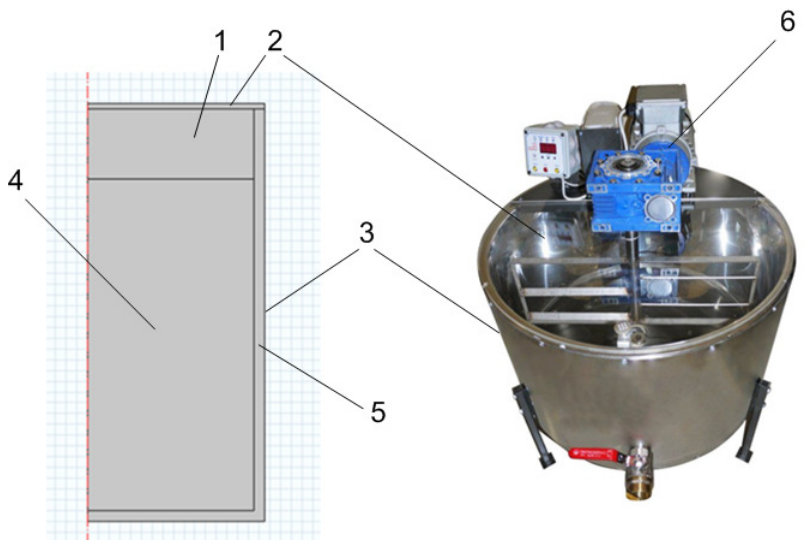

Fig. 2. Geometric model of honey recrystallizer in Comsol: 1 - air; 2 - plexiglass cover; 3 - stainless steel recrystallizer body; 4 - honey; 5 - thermal insulation; 6 - electric drive

After creating the geometry, each of the five components of the model were given materials with real physical parameters such as density, thermal conductivity, heat capacity, viscosity and the adiabatic value for air and honey. The dependencies of honey density and thermal conductivity on temperature were also given. The properties of buckwheat honey were taken as a basis. Initial honey temperature was assumed to be $20^{\circ} \mathrm{C}$. The power of the heaters was taken to be $400 \mathrm{~W}$. A thin layer at the contact between honey and the case was specified as heaters.

The physical interfaces used were "Heat Transfer in Solids" for determining the temperature fields in the installation and "Laminar Flow" for determining the air velocity in the air layer between the cover and honey. 


\section{Results and discussion}

The results of calculation are presented in the form of surfaces of temperature distribution inside the recrystallizer in time (Fig. 3), as well as in the form of graphs of change of average and maximum honey temperatures in time (Fig. 4).
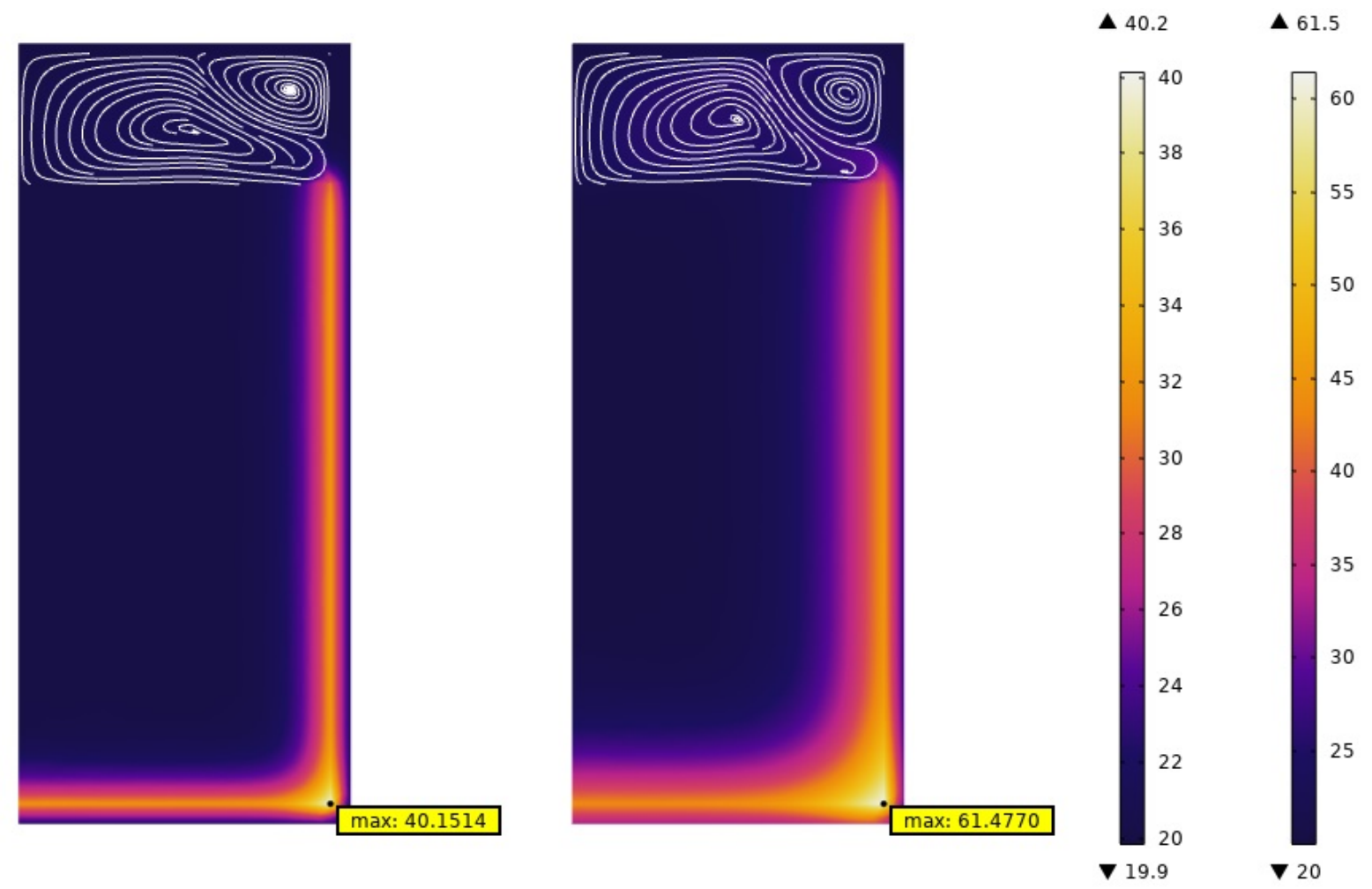

Fig. 3. Calculation result after 34 minutes of honey heating (left) and after 120 minutes (right)

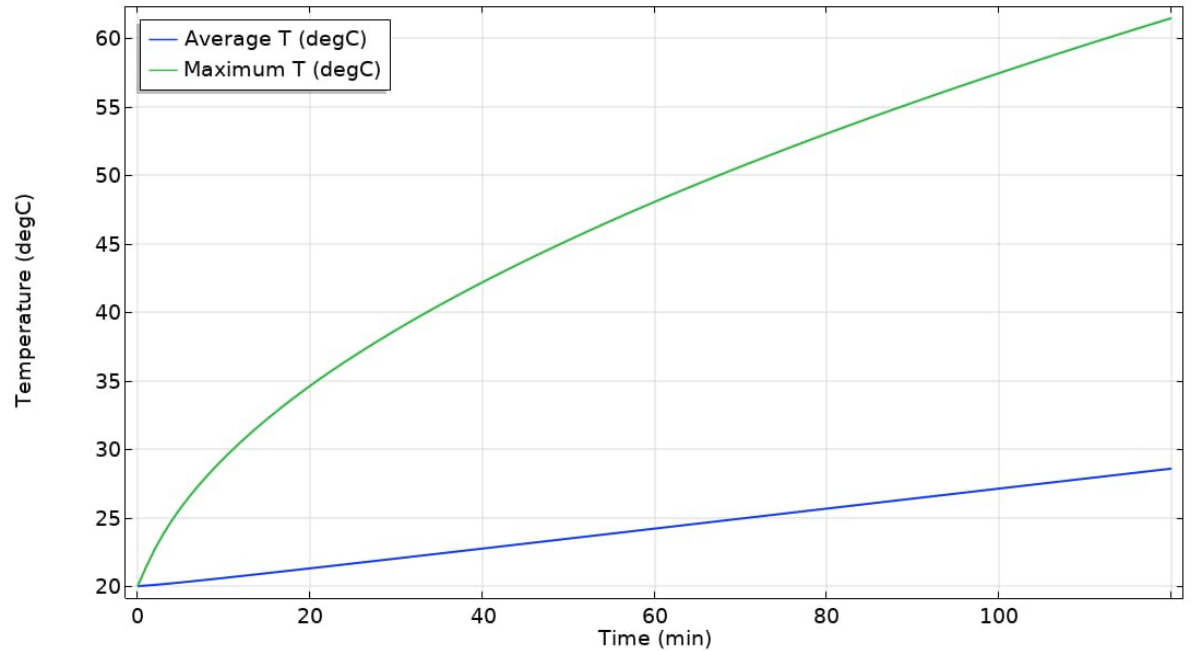

Fig. 4. Plots of changes in average and maximum honey temperature in time

Researches of the received model have shown that after 34 minutes, after the beginning of the recrystallization process, honey in the bottom corner of the recrystallizer begins to overheat and its temperature becomes above $40{ }^{\circ} \mathrm{C}$ that, as it is known, leads to decrease in the quality of the product. Therefore, according to the received data the technological process of honey mixing should be performed not later than 34 minutes after the beginning of work. This calculation also makes it possible to justify the location of the temperature sensor to regulate the heating of honey without losing its quality. The sensor should be placed in the bottom corner of the honey recrystallizer, as this is where honey can get the most overheated before mixing. After 120 minutes of operation without 
stirring and regulating the temperature honey will be heated over $61^{\circ} \mathrm{C}$, which will reduce the diastase activity and increase oxymethylfurfurol.

It should be noted that, while creating the model, we faced the fact that it is very difficult to find the dependencies of such honey parameters as the heat capacity, heat conductivity and the density on temperature. In addition, these parameters are very different not only from the type of honey, but also from its humidity and condition. It is, therefore, imperative that these parameters be examined first, before drawing any conclusions about a honey variety based on the developed model.

\section{Conclusions}

The approach to selection of parameters and operation modes of the honey recrystallizer should be scientifically grounded in order to preserve the quality of the product and increase its competitiveness. The model of honey heating in the recrystallizer, developed in Comsol Multiphysics software product, takes into account the thermophysical parameters of honey, geometrical dimensions of the recrystallizer and allows to justify the maximum possible time before the start of honey mixing when it is heated.

The developed model used the properties of buckwheat honey. According to them, buckwheat honey should be stirred in the recrystallizer after 34 minutes of the heating process. The location of the temperature sensor in the recrystallizer under consideration should be in the lower corner and not in the centre of the bottom as in existing installations.

\section{References}

[1] Оськин С.В., Овсянников Д.А. Способы повышения производительности труда в пчеловодстве (Ways to increase productivity in beekeeping). Collection of articles on the materials of the 71st scientific-practical conference of teachers on the results of research for 2015. Krasnodar: Kuban State Agrarian University, 2016. pp. 335-336. (In Russian).

[2] Николаенко С.А., Цокур Д.С. Повышение продуктивности пчеловодства (Beekeeping productivity increase). Russian Journal: Mechanization and Electrification of Agriculture, 2015, No10. pp. 13. (In Russian).

[3] Zaikina, V.I. Examination of honey and methods of its falsification detection. Third edition. Moscow: Dashkov and K ${ }^{\circ}, 2012.168$ p.

[4] Enzo Alberto Tosi, Re E., Lucero H. etc. Effect of honey high-temperature short-time heating on parameters related to quality, crystallisation phenomena and fungal inhibition. LWT- Food Science and Technology, 2004, No37(6). pp. 669-678.

[5] Nair S. The effect of heat treatment on the quality of Algerian honey. Researcher, 2016, No8(9). pp. 1-6.

[6] Hebbar U.H., Nandini K.E., Lakshmi M.C. etc Microwave and Infrared Heat Processing of Honey and Its Quality. Food Science and Technology Research, 2003, No 9(1). pp. 49-53.

[7] Turkmen N., Sari F., Poyrazoglu E.S. etc. Effects of prolonged heating on antioxidant activity and colour of honey. Food Chemistry, 2006. pp. 653-657.

[8] Tosi E., Ciappini M., Re E., etc Honey thermal treatment effects on hydroxymethylfurfural content. Food Chemistry, 2002. pp. 71-74.

[9] Horne. X., Lullmann K. All about honey: production, receiving, ecological purity and sale. Moscow: Astrel; Vladimir: VKT, 2011. 316 p.

[10] CFD Module User's Guide. COMSOL.

[11] Heat Transfer Module User's Guide. COMSOL. 